Asia Proceedings of Social Sciences

(APSS)

www.readersinsight.net/APSS

\title{
Mediation Model of Interrelationships among 4 C's of Work Environment, Employee Performance and Organizational Performance in Pakistani Organizations
}

\author{
Saima Aftab* \\ Business and Technology Department, Foundation University, \\ Pakistan \\ Komal Khalid \\ Faculty of Economics and administration, King Abdul Aziz University \\ Kingdom of Saudi Arabia
}

*Corrosponding author's Email: saima.aftab@fui.edu.pk

Peer-review under responsibility of $4^{\text {th }}$ Asia International Conference 2018 editorial board

(http://www.utm.my/asia/our-team/)

(C) 2018 Published by Readers Insight Publisher,

lat 306 Savoy Residencia, Block 3 F11/1,44000 Islamabad. Pakistan,

info@ readersinsight.net

This is an open access article under the CC BY-NC-ND license (http://creativecommons.org/licenses/by-nc-nd/4.0/). 


\section{Rese a r ch H igh I ights}

Objective and subjective aspects of Individual and Organizational performances (Valmohammadi \& Roshanzamir, 2015) has been focus of research arena at number of instances to conclude about micro, meso and macro level phenomenas within organziations. This study aims to provide a unique outlook on $4 \mathrm{C}$ 's of work environment (meso) and their interrelationship with Organizational Performance through i-e individual performance (micro). Career planning, Consultative management, Communication and Culture (performance oriented) are taken as 4 important C's, constituting a comprehensive whole of Work environment. The study proposed two research hypotheses. Data was collected through 5 point Likert scale questionnaires, from 297 employees of 42 manufacturing and services sector firms in Pakistan. Bivariate Pearson's Correlation, Preacher and Hayes Process v 3.0, Model 4, and Bootstrapping is used for data analysis. Results indicate that all four C's of work environment have strong positive correlation with organziational perfomance through individual performance acting as a mediator.

\section{Graphical A bstract}

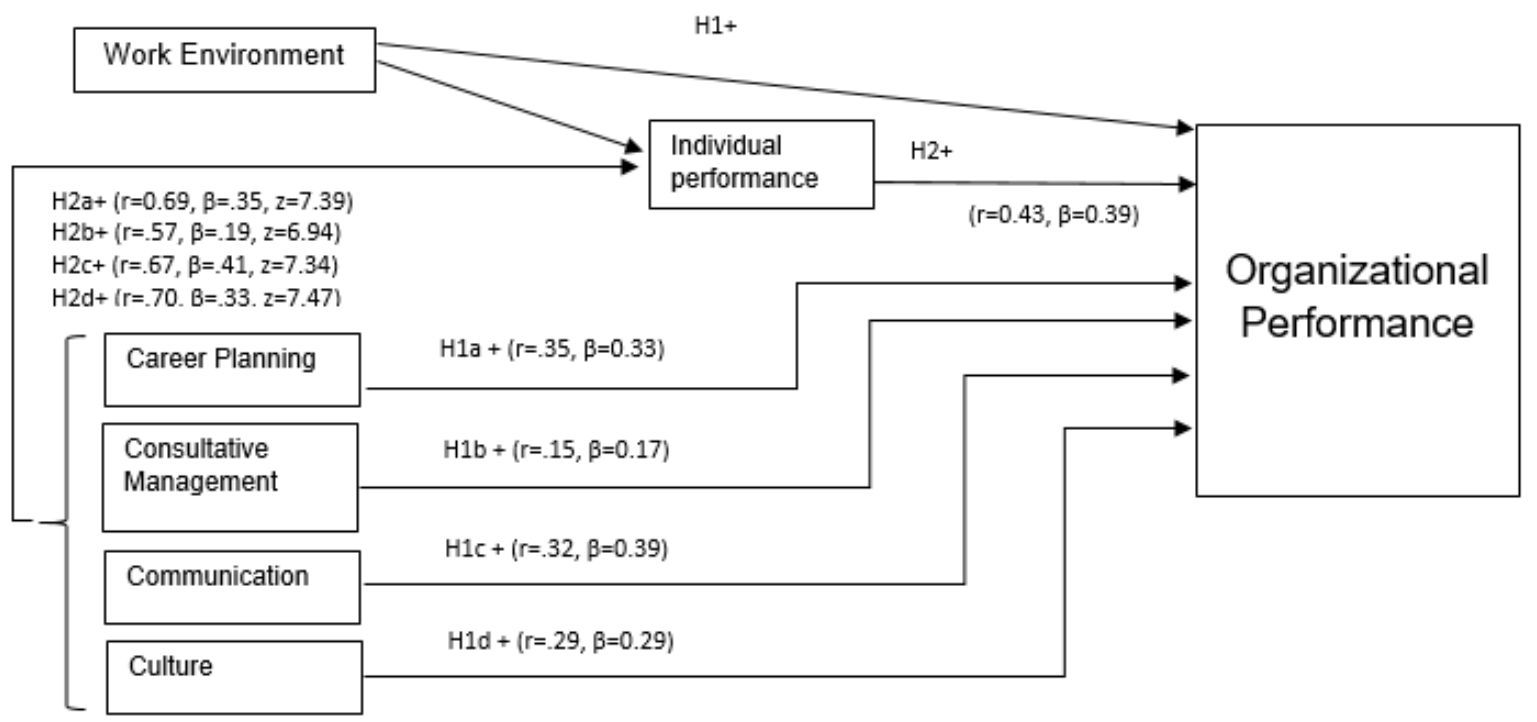




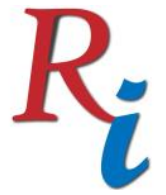

Asia Proceedings of Social Sciences

(APSS)

www.readersinsight.net/APSS

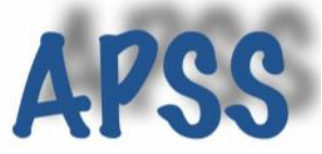

\section{Research Objectives}

Businesses these days aim for providing supportive work environments for employees (Raziq \& Maulabakhsh, 2015) in order to facilitate goal achievement (Awan \& Tahir, 2015; Chandrasekar, 2011). The purpose of this research study is to present a theoretical model for interralationships among Work environment factors (career planning, consultative management, communication, Culture), individual performance and organziational performance, which will help manufacturing and service sector organizations to identify the pivotal environmental factors used to enhance the performance of employees at work (Raziq $\&$ Maulabakhsh, 2015). This study focuses on objective aspect of individual performance with respect to system performance. The objective is to observe the interdependencies of environmental factors and organziational performance through enhanced individual performance. To the best knowledge and understanding of the researcher there is no study that presents a unique model like this study did. The model is tested in Pakistani business environment because of consistent challenges posed and constancy need of the economy and its dependency on industry to help develop a stable economy, as manufacturing and service sectors are the major contributors in overall performance of economy at national level.

\section{Methodology}

A homogenous population of middle managers working in manufacturing and service sectors of Pakistan was selected for the study. 5 point Likert ScaleQuestionnaires were used for the purpose of data collection. A total of 420 questionnaires were distributed with a ratio of 10 questionnaires in each organziation. Out of 420 questionnaires, 297 were used for data analysis after cleaning the data using Cooks's Distance and Central Leverage Value method, with a resopnse rate of $70.71 \%$. Surveys conducted included information regarding respondent demographics (age, gender, income, education, marital status). Principal component analysis and rotation component matrix through Varimax with Kaiser Normalization was perfromed to assess fitness for good for the proposed model and to determine the fitness of scales used. All extraction values were above 0.5 indicating that variables are significantly defined and there is no multicollinearity. Data analysis was performed using SPSS-23 and tests of Pearson's Correlation, PROCESS by SPSS (Preacher, Rucker, \& Hayes, 2007) and Bootstrapping (Hayes, 2009) were used. 


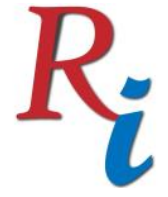

\section{Asia Proceedings of Social Sciences \\ (APSS) \\ www.readersinsight.net/APSS}

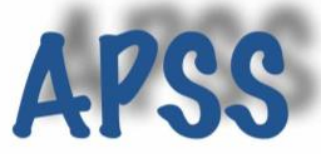

\section{Results}

Results show that majoity of respondents were males (79.1\%), with ages ranging from 31-40 years $(49.5 \%)$, holding bachlors degree $(50.5 \%)$, married $(62 \%)$, from middle level management $(75.4 \%)$, with current organizational stay of 2-5 yrs. (53.2\%) with permanent employment status (83.5\%). Mean and Standard deviation values of variables showed that all variables are above average values. Skewness and Kurtosis values lie between +1 and -1 indicating normality of data. Correlation results show that all four factors of WE have highly significant correlation $(\mathrm{CP}=0.69, \mathrm{CM}=0.57, \mathrm{COM}=0.67, \mathrm{CUL}=0.70)$ with $\mathrm{IP}$ but a weaker but significant relationship with $\mathrm{OP}(\mathrm{CP}=0.35, \mathrm{CM}=0.15, \mathrm{COM}=0.32$, Culture $=0.29)$. IP has a highly significant correlation with OP i.e. .43 at $\mathrm{p}<.01$ (2-tailed). Culture has the strongest correlation $(R=.70$ at $p<0.01)$ with IP. Results of PROCESS show that $C P(\beta=0.33), C M$ $(\beta=0.17), \operatorname{COM}(\beta=0.39)$, and CUL $(\beta=0.29)$, influence OP in a significantly positive manner, WE influences IP, IP is related to OP $(\beta=.39, p<.00)$ and direct effect of WE on OP is less than the indirect effect of WE on OP, hence predicting full mediation. Bootstrapping results indicate that all indirect paths were highly significant.

\section{Findings}

Keeping in view the results all hypotheses (H1a, b, c, d, H2a, b, c, d) are accepted. The organziations, who need to be effective and profitable, demand a strong unified interaction of all $4 \mathrm{C}$ 's of WE, with strong influence on achieving individual and organziational perfromance excellence. This study will help HR practitioners to ponder over how to create a right mix of WE factors which can help attract and retain quality individuals depending upon their personality types, traits and job titles (micro level) and may vary according to erratic internal and external environments of the organziation (macro level).

\section{References}

Awan, A. G., \& Tahir, M. T. (2015). Impact of working environment on employee's productivity: A case study of Banks and Insurance Companies in Pakistan. European Journal of Business and Management, 7(1), 329-345. 


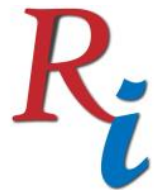

\section{Asia Proceedings of Social Sciences}

(APSS)

www.readersinsight.net/APSS

Chandrasekar, K. (2011). Workplace environment and its impact on organisational performance in public sector organisations. International journal of enterprise computing and business systems, 1(1), 1-19.

Hayes, A. F. (2009). Beyond Baron and Kenny: Statistical mediation analysis in the new millennium. Communication monographs, 76(4), 408-420.

Preacher, K. J., Rucker, D. D., \& Hayes, A. F. (2007). Addressing moderated mediation hypotheses: Theory, methods, and prescriptions. Multivariate behavioral research, 42(1), 185-227.

Raziq, A., \& Maulabakhsh, R. (2015). Impact of working environment on job satisfaction. Procedia Economics and Finance, 23, 717-725.

Valmohammadi, C., \& Roshanzamir, S. (2015). The guidelines of improvement: Relations among organizational culture, TQM and performance. International Journal of Production Economics, 164, 167-178. 